Goldschmidt 2021 Abstract

https://doi.org/10.7185/gold2021.8125

\section{Geochemical Assessment of local limestone rocks for using as neutralization cover material in a Mine Waste Pile, Peru}

\author{
SHEYLA B. PALOMINO-ORE ${ }^{1}$, PABLO QUESADA \\ OLORIZ $^{1}$, MARIEL SAMANEZ ${ }^{1}$, WENDI MORALES \\ ESPIRITU $^{1}$ AND ERICK REÁTEGUI KLEMBERGTH ${ }^{2}$ \\ ${ }^{1}$ Amphos 21 Consulting Peru SAC \\ ${ }^{2}$ Independent Consultant
}

Presenting Author: sheyla16@vt.edu

The mining of metal ores generates solid wastes which produce potential acid mine drainage with high concentration of toxic metals causing negative impacts into rivers and communities in the area. The cover systems are used to control these problems, ensuring the isolation of waste, limiting the influx of atmospheric water and/or oxygen and permitting the chemical stabilization through a good geochemical cover characterization and classification. In this paper, the evaluated cover material was the limestone available in the area as quarries. The objective was to characterize and classified these materials prioritizing their geochemical neutralization capacity and obtain the chemical stability in the mine waste piles.

The mine ore is a highly sulphurated epithermal deposit where the mineral exploited is the gold. Mine waste is composed of, besides quartz and potassium feldspar (orthoclase), carbonates (calcite), oxides (hematite, goethite and pyrolusite), and sulfides (pyrite, sphalerite, chalcopyrite, and galena). On the other hand, limestone materials obtained from quarries have calcium content percent of $50 \%$ and $62 \%$ respectively. Tests performed to determine its physicochemical parameters and their variability on limestone were: Acid Base accounting (ABA), Whole Rock Analysis (WRA), Sequential Extraction and minerology. Acid mine drainage (AMD) in the mine waste pile was characterized by a low $\mathrm{pH}(\sim 5.5)$, high manganese concentration $(\sim 0.30 \mathrm{mg} / \mathrm{L})$, lead concentration $(\sim 0.70 \mathrm{mg} / \mathrm{L})$, zinc concentration $(\sim 0.80$ $\mathrm{mg} / \mathrm{L})$, and high sulfate content $(\sim 1300 \mathrm{mg} / \mathrm{L})$. In contrast, ABA test showed that limestone materials evaluated have an average neutralization potential of $580 \mathrm{Kg} \mathrm{CaCO}_{3} /$ Ton.

In conclusion, the geochemical assessment of the limestone material located in the surroundings of the mine facility indicated that this material can be used as a complementary cover providing adequate neutralization capacity and obtaining the chemical stability of the mine waste pile. As recommendation, it is necessary to complement the study with the evaluation of volume material available in the area and the constructive design of the disposition into the pile.
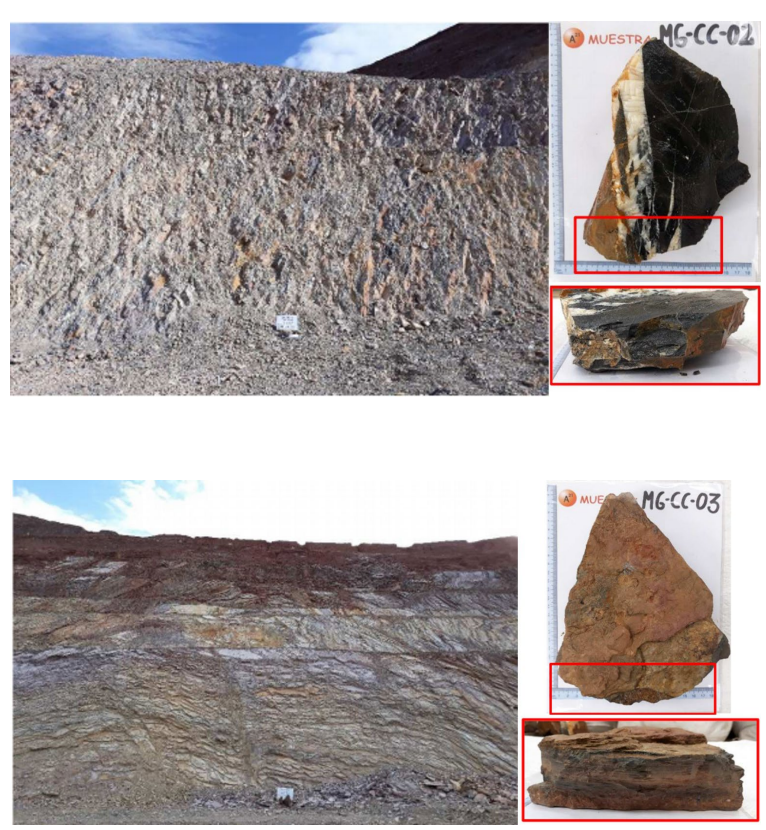